\title{
TESTE DE RAIOS X PARA AVALIAÇÃO DO POTENCIAL FISIOLÓGICO DE SEMENTES DE IPÊ-ROXO ${ }^{1}$
}

\author{
JULIA BISSOLI DO AMARAL ${ }^{2}$, LEILA MARTINS ${ }^{3}$, VICTOR AUGUSTO FORTI4, \\ SILVIO MOURE CÍCERO ${ }^{5}$, JULIO MARCOS FILHO ${ }^{5}$
}

\begin{abstract}
RESUMO - Em espécies multiplicadas comercialmente via semeadura indireta, como várias essências florestais, a utilização de sementes de alto potencial fisiológico é imprescindível para garantir o desenvolvimento e estabelecimento adequado das plantas no campo. Assim, diversas técnicas têm sido utilizadas para avaliar a integridade das sementes e, dentre elas, o teste de raios $\mathrm{X}$. O objetivo no trabalho foi avaliar o potencial fisiológico das sementes de ipê roxo (Tabebuia heptaphylla), após separação por cor e tamanho, por meio dos testes de raios X e de germinação. As sementes foram classificadas pela cor, utilizando carta de cor de Munsell, e tamanho, utilizando peneira de crivos oblongos, obtendo-se materiais das frações amarelo-claro maiores, amarelo-claro menores, amarelo-escuras maiores, amarelo-escuras menores, mistura de amarelo-claro maiores, amarelo-claro menores e amarelo-escuro maiores e testemunha (sem classificação). Em seguida, as sementes das diferentes frações, foram submetidas a avaliações da integridade física e viabilidade, por meio de teste de raios X e de germinação, respectivamente. Adotou-se delineamento experimental inteiramente casualizado, com seis tratamentos e cinco repetições, comparando-se as médias pelo teste de Scott-Knott $(\mathrm{p} \leq 0,05)$. O teste de raios $\mathrm{X}$ é eficiente na avaliação da morfologia interna de sementes de ipê-roxo e sua relação com o potencial fisiológico. A coloração e o tamanho das sementes de ipê-roxo influenciam o potencial fisiológico das mesmas.
\end{abstract}

Termos para indexação: Tabebuia heptaphylla, análise de imagens, sementes florestais, produção. de mudas.

\section{X-RAY TEST TO EVALUATE THE PHYSIOLOGICAL POTENTIAL OF Tabebuia Heptaphylla SEEDS}

\begin{abstract}
The use of seeds with a high physiological potential is essential to guarantee proper field establishment and seedling development. Several techniques have been used to evaluate seed quality including the X-ray test. The objective of this study was to evaluate the physiological potential of Tabebuia heptaphylla seeds with X-ray and germination tests after grading by color and size. Seeds were classified using the Munsell color chart and screens, in light-yellow larger, light-yellow smaller, dark-yellow larger, dark-yellow smaller, mixture of light-yellow larger, light-yellow smaller and dark-yellow larger and control. Seeds from
\end{abstract}

${ }^{1}$ Submetido em 02/09/2010 e aceito para publicação em 13/04/2011. Trabalho realizado com auxílio financeiro da FAPESP.

${ }^{2}$ Eng. Agrícola, Pós-Graduada em Gestão Integrada, UNISAL, email: julibamaral@gmail.com

${ }^{3}$ Eng. Agrônoma, Dr., Laboratório Central de Sementes e Mudas, Departamento de Sementes Mudas e Matrizes - CATI. Caixa Postal 962,
CEP 13070-178, Campinas, SP, Brasil, email: leila@cati.sp.gov.br ${ }^{4}$ Eng. Agrônomo, M.S., Programa de Pós-Graduação em Fitotecnia, USP/ ESALQ, email: viaugu@yahoo.com.br; autor para correspondência.

${ }^{5}$ Eng. Agrônomo, Dr., Professor Titular, Departamento de Produção Vegetal, USP/ESALQ, bolsista do CNPq, Caixa Postal 09, CEP 13418900, Piracicaba,SP, Brasil, e-mail: smcicero@esalq.usp.br, jmarcos@ esalq.usp.br 
different fractions were then submitted to X-ray and germination tests. The experimental design was completely randomized with six treatments and five replicationsand mean values were compared by the Scott-Knott test $(\leq 5 \%)$. Results showed that the X - ray test effectively evaluates the internal morphology of Tabebuia heptaphylla seeds and its relationship with physiological potential. Seed color and size affect the physiological potential of Tabebuia heptaphyla seeds.

Index terms: Tabebuia heptaphylla, image analysis, forest seeds, seedling production.

\section{INTRODUÇÃO}

O ipê-roxo (Tabebuia heptaphylla (Vell.) Toledo), espécie popularmente conhecida como ipê-roxo-de-setefolhas e ipê-preto, é uma Bignoniaceae de porte arbóreo, alcançando entre 10 e $20 \mathrm{~m}$ de altura; seu florescimento é abundante e, com a queda das folhas, maciças e vistosas florações proporcionam um efeito paisagístico de rara beleza. Além disso, tem importante valor econômico considerando-se a durabilidade e a resistência de sua madeira utilizada em construções e confecções de vigas e assoalhos (Lorenzi, 2002) e tem sido indicada para trabalhos de restauração de ecossistemas florestais (Resolução da Secretaria de Meio Ambiente No 47 de 26 de novembro de 2003) e de paisagismo. Dessa forma, a utilização de sementes é alta de qualidade na formação de mudas é de suma importância e merece destaque, visto que a multiplicação se dá essencialmente por via sexuada.

Para a avaliação do potencial fisiológico em sementes florestais, o teste de germinação pode ser um entrave, considerando a variabilidade genética que essas espécies apresentam e o longo tempo demandado para a obtenção dos resultados (Masetto et al., 2008). Uma das técnicas empregadas na análise de sementes é a de raios X, cujo estudo foi iniciado na Suécia, em 1953, por Simak e Gustafsson, com sementes de Pinus sylvestris L. Posteriormente, o teste tem sido utilizado e aperfeiçoado, uma vez que possibilita a obtenção de informações sobre a ocorrência de sementes mal formadas e vazias, as quais podem influenciar os resultados de germinação. O teste de raios $\mathrm{X}$ também possibilita a visualização da posição, forma e danificações que ocorrem no eixo embrionário das sementes (Cícero et al., 1998; Carvalho et al. 1999; Obando Flor, 2000); considerado um método rápido e não destrutivo, é indicado desde os anos 80 pela ISTA -
“International Seed Testing Association" (ISTA, 2009).

Essa técnica vem sendo aprimorada e já foi comprovada a sua eficiência na identificação de características invisíveis a olho nu em sementes de Cedressa fissilis Vell. (Masetto et al., 2008); Peltophorum dubium (Oliveira et al., 2003) e Lithraea molleoides (Machado e Cícero, 2003). Esses autores, adicionalmente, salientaram que o descarte de sementes danificadas pode melhorar a germinação do lote. O uso do teste de raios X, em sementes do gênero Tabebuia, pode trazer contribuições tecnológicas, já que aspectos morfológicos dessas sementes impedem a visualização de embriões defeituosos ou mesmo de sementes vazias (Oliveira et al., 2004).

Durante o processo de maturação, as sementes passam por modificações físicas, bioquímicas e fisiológicas, influenciadas por fatores genéticos e ambientais até atingir o ponto de maturidade fisiológica, cuja identificação é importante para definir o momento de colheita de espécies colhidas manualmente (Carvalho e Nakagawa, 2000). Exames visuais permitiram observar que existe variabilidade de coloração e tamanho nas sementes de T. heptaphylla; dessa forma, variáveis como tamanho, densidade, forma, textura e coloração, utilizadas nas separações realizadas durante o beneficiamento, podem constituir indicativos do potencial fisiológico das sementes (Vaughan et al., 1976). Por exemplo, Gemarque et al. (2002) observaram máxima germinação e vigor em sementes de Tabebuia impetiginosa de cor verde-amareloamarronzadas e frutos verde com pontos arroxeados.

Assim, o objetivo dos autores com este trabalho foi o de avaliar o potencial fisiológico das sementes de ipê roxo, por meio dos testes de raios $\mathrm{X}$ e de germinação, após classificação em frações de diferentes tamanhos e colorações. 


\section{MATERIAL E MÉTODOS}

A pesquisa foi realizada no Laboratório Central de Sementes e Mudas do Departamento de Sementes, Mudas e Matrizes (LCSM/DSMM) da Coordenadoria de Assistência Técnica Integral (CATI), em Campinas - SP e Laboratório de Análise de Imagens da Escola Superior de Agricultura "Luiz de Queiroz", USP/ESALQ, em Piracicaba - SP, com sementes provenientes do Núcleo de Produção de Mudas de Pederneiras (DSMM/CATI), em Pederneiras - SP.

Os frutos foram coletados maduros, quando apresentavam coloração verde-amarelo-amarronzada e as vagens estavam ainda fechadas, de quinze plantasmatrizes e colocados em ambiente sombreado para secagem e posterior extração das sementes. A seguir, as sementes foram separadas pela cor, com o uso de carta de cor de Munsell, e pelo tamanho, utilizando peneiras, constituindo seis tratamentos: T1 - população inicial (testemunha); T2 - amarelo-claro maiores (tonalidade mais clara em relação à cor padrão 10 YR 5/3 e que ficaram retidas em peneira com crivos oblongos de $4,73 \mathrm{~mm}$ de largura e 16,60 mm de comprimento); T3 - amarelo-claro menores (tonalidade mais clara em relação à cor padrão 10YR 5/3 e que passaram em peneira de crivo oblongo com 4,73 $\mathrm{mm}$ de largura e $16,60 \mathrm{~mm}$ de comprimento); T4 - amarelo-escuro maiores (tonalidade igual ou mais escura em relação à cor padrão $10 \mathrm{YR} 5 / 3$ e que ficaram retidas em peneira com crivo oblongo de $4,73 \mathrm{~mm}$ de largura e 16,60 mm de comprimento); T5 - amareloescuro menores (tonalidade igual ou mais escura em relação à cor padrão $10 \mathrm{YR} 5 / 3$ e que passaram por peneira de crivo oblongo de $4,73 \mathrm{~mm}$ de largura e $16,60 \mathrm{~mm}$ de comprimento); T6 - mistura dos tratamentos T2, T3 e T4. As sementes maiores, após separação apresentavam, em média, 23,8 mm de comprimento, 4,9 $\mathrm{mm}$ de largura, 1,1 $\mathrm{mm}$ de espessura e massa de mil sementes de $24,28 \mathrm{~g}$; as sementes menores, 19,4 mm de comprimento, 4,3 $\mathrm{mm}$ de largura, 1,0 $\mathrm{mm}$ de espessura e massa de mil sementes de $11,79 \mathrm{~g}$.

Após a obtenção de todos os tratamentos, as sementes foram submetidas a testes de raios $\mathrm{X}$ e de germinação.

Raios X: cinco sub-amostras de 30 sementes, para cada tratamento, foram colocadas em alvéolos individualizados de uma placa de acrílico e submetidas à radiação com intensidade de $10 \mathrm{kv}$ durante 300 segundos aos $57 \mathrm{~cm}$ da fonte emissora, utilizando aparelho Faxitron X-ray, modelo MX-20, para a obtenção das radiografias.
As sementes foram numeradas de acordo com a posição ocupada na placa de acrílico, de maneira que pudessem, posteriormente, ser identificadas na condução do teste de germinação. Os filmes radiográficos foram revelados em uma reveladora automática Hope X-Ray, modelo 319 MicroMax e, a seguir, as imagens foram capturadas por um Scanner Umax, modelo Powerlook 1100, para a ampliação e melhor visualização no computador. A seguir, para a avaliação das imagens obtidas por meio do teste de raios $\mathrm{X}$, foi considerado o preenchimento da cavidade embrionária das sementes conforme critério apresentado a seguir.

- Nota 1: cavidade embrionária totalmente preenchida, com eixo embrionário e cotilédones bem formados.

- Nota 2: cavidade embrionária com mais de 50\% de preenchimento, com eixo embrionário e cotilédones bem formados.

- Nota 3: cavidade embrionária com mais de 50\% de preenchimento, com eixo embrionário e, ou cotilédones mal formados.

- Nota 4: cavidade embrionária com menos de $50 \%$ de preenchimento, com eixo embrionário e cotilédones bem formados.

- Nota 5: cavidade embrionária com menos de 50\% de preenchimento e com eixo embrionário e, ou cotilédones mal formados.

- Nota 6: cavidade embrionária vazia.

Germinação: as sementes provenientes do teste de raios $\mathrm{X}$ foram distribuídas em 15 grupos de 10, sobre duas folhas de papel-toalha, no terço superior do substrato, cobertas com mais uma folha de papel-toalha e enroladas. As folhas de papel foram umedecidas com quantidade de água equivalente a 2,5 vezes a massa das mesmas. Os rolos foram mantidos aos $25{ }^{\circ} \mathrm{C}$ em câmara BOD com 8 horas de luz e 16 horas de escuro. As avaliações foram feitas aos 11, 16 e 28 dias após a instalação do teste e os dados de germinação foram expressos em porcentagem de plântulas normais (Brasil, 2009).

O delineamento experimental foi inteiramente casualizado com seis tratamentos e cinco repetições, com as médias comparadas pelo teste de Scott-Knott (p $\leq 5 \%)$.

\section{RESULTADOS E DISCUSSÃO}

Pelo exame das imagens de raios $\mathrm{X}$ das sementes de T. heptaphylla, na Tabela 1, observa-se que 
a maioria das sementes classificadas com notas 1 (cavidade embrionária totalmente preenchida, com eixo embrionário e cotilédones bem formados (Figura 1a) ou 2 (cavidade embrionária com mais de $50 \%$ de preenchimento, com eixo embrionário e cotilédones bem formados) originaram plântulas normais, independentemente do tratamento (Figura 1b). Conforme Burg et al. (1994), algumas sementes que apresentam características normais no teste de raios X (Figura 1a), podem apresentar problemas na germinação, possivelmente por infecções invisíveis com microrganismos e sementes fisiologicamente comprometidas ou mortas, devido à deterioração. Adicionalmente, de acordo com Socolowski et al. (2008), as sementes que emitiram a raiz primária e não formaram plântulas normais poderiam estar em estádio inicial de perda de viabilidade. Copeland (1976) e Simak et al. (1989), relataram que apesar do teste de raios-X não ser específico para avaliar viabilidade, ele pode revelar danos morfológicos que podem afetar o potencial fisiológico.

TABELA 1. Germinação (plântulas normais e notas 1 e 2 atribuídas às imagens das sementes no teste de raios $\mathrm{X}$ ) em sementes de ipê-roxo separadas por coloração e tamanho (T1testemunha, $T 2$ - sementes amarelo-claro maiores, T3 - sementes amarelo-claro menores, T4 - sementes amarelo-escuro maiores, T5- sementes amarelo-escuro menores e T6 - mistura dos tratamentos T2, T3 e T4).

\begin{tabular}{ccc}
\hline \multicolumn{3}{c}{ Germinação $(\%)$} \\
\hline Tratamentos & Plântulas normais & Notas 1 e 2 \\
\hline T1 & $61 \mathrm{a}$ & $68 \mathrm{~b}$ \\
T2 & $73 \mathrm{a}$ & $83 \mathrm{a}$ \\
T3 & $51 \mathrm{~b}$ & $55 \mathrm{~b}$ \\
T4 & $46 \mathrm{~b}$ & $64 \mathrm{~b}$ \\
T5 & $63 \mathrm{a}$ & $71 \mathrm{~b}$ \\
T6 & $75 \mathrm{a}$ & $82 \mathrm{a}$ \\
\hline CV (\%) & 16,84 & 16,11 \\
\hline
\end{tabular}

Na coluna, médias seguidas de mesma letra, não diferem entre si pelo teste de Scott-Knott no nível de 5\% de probabilidade.
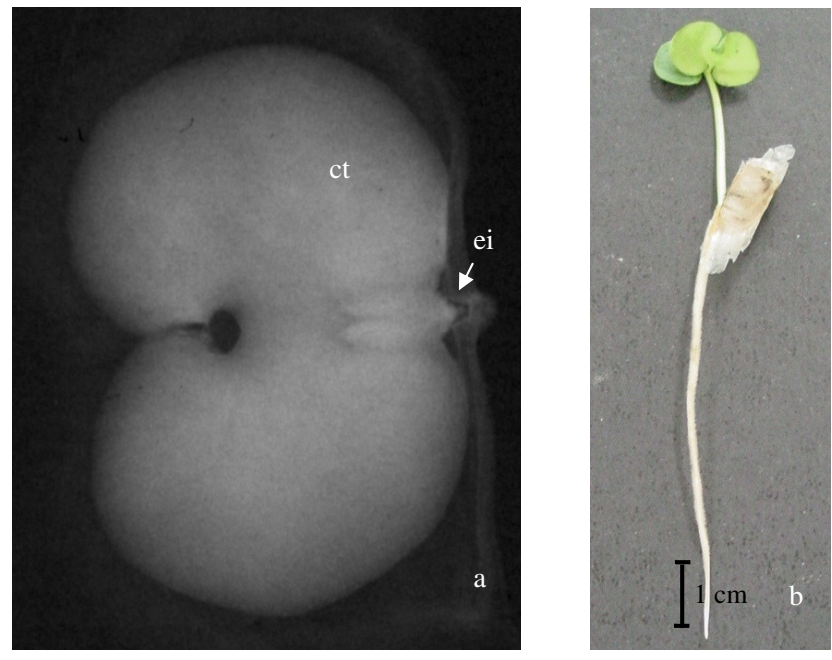

FIGURA 1. Semente de ipê-roxo avaliada por meio do teste de raios $X$, com a cavidade embrionária totalmente preenchida e com eixo embrionário e cotilédones bem formados (a) originando uma plântula normal (b). ct - cotilédone; ei - eixo embrionário.

$\mathrm{Na}$ Tabela 2, onde estão os dados das sementes classificadas com notas 3 (cavidade embrionária com mais de $50 \%$ de preenchimento, com eixo embrionário e, ou cotilédones mal formados) e 4 (cavidade embrionária com menos de $50 \%$ de preenchimento, com eixo embrionário e cotilédones bem formados), verifica-se que a maioria destas originou plântulas anormais. As sementes amareloescuro maiores (T4) apresentaram os maiores valores de plântulas anormais e de sementes classificadas com notas 3 e 4, diferindo dos demais tratamentos. Na Figura 2a observa-se a imagem de uma semente classificada como nota 3, originando uma plântula anormal após o teste de germinação (Figura 2b).

Já a Tabela 3 mostra que praticamente todas as sementes caracterizadas com notas 5 (cavidade embrionária com menos de $50 \%$ de preenchimento e com eixo embrionário e, ou cotilédones mal formados) ou 6 (cavidade embrionária vazia) originaram sementes mortas. Conforme Socolowski et al. (2008), a massa das sementes é um indicador de sua qualidade fisiológica $\mathrm{e}$ as imagens de raios $\mathrm{X}$ são importantes para a observação da qualidade física das sementes, ocorrência similarmente constatada por Masetto et al.(2007) nas imagens de Eugenia pleurantha. A Figura 
3a representa uma semente classificada com a nota 6 originando, após o teste de germinação, uma semente morta (Figura 3b). Assim, de forma semelhante ao observado por Oliveira et al. (2004) em sementes de ipê-amarelo (Tabebuia serratifolia Vahl Nich.) e ipê-roxo (Tabebuia impetiginosa (Martius ex A. P. de Candolle) Standley, o teste de raios $\mathrm{X}$ foi eficiente na avaliação do potencial fisiológico em sementes de ipê-roxo (Tabeuia heptaphylla) e os defeitos internos detectados nas radiografias afetaram a germinação, reduzindo a qualidade do lote.

Em relação ao método estabelecido para a classificação das sementes, por cor e peneira, verifica-se que os tratamentos 3 (sementes amarelo-claro menores) e 4 (sementes amarelo-escuro maiores) foram os que apresentaram valores inferiores de plântulas normais (Tabela 1), sendo que as sementes do tratamento 3 tiveram valores superiores na classificação com notas 5 e 6 , originando sementes mortas (Tabela 3). Dessa forma, os resultados mostraram que a coloração das sementes pode indicar o grau de maturidade fisiológica. Como observado nos dados do teste de raios $\mathrm{X}$, as sementes amarelo-claro menores apresentaram alta porcentagem de sementes com eixo embrionário mal formado, sugerindo menor potencial fisiológico em relação às demais sementes.

TABELA 2. Germinação (plântulas normais e notas 3 e 4 atribuídas às imagens das sementes no teste de raios $X$ ) de sementes de ipê-roxo separadas por coloração e tamanho (T1testemunha, T2 - sementes amarelo-claro maiores, T3 - sementes amarelo-claro menores, T4 - sementes amarelo-escuro maiores, T5- sementes amarelo-escuro menores e T6 - mistura dos tratamentos T2, T3 e T4).

\begin{tabular}{ccc}
\hline \multicolumn{3}{c}{ Germinação (\%) } \\
\hline Tratamentos & Plântulas anormais & Notas (3 e 4) \\
\hline T1 & $3 \mathrm{~b}$ & $4 \mathrm{~b}$ \\
T2 & $2 \mathrm{~b}$ & $3 \mathrm{~b}$ \\
T3 & $1 \mathrm{~b}$ & $0 \mathrm{~b}$ \\
T4 & $16 \mathrm{a}$ & $10 \mathrm{a}$ \\
T5 & $2 \mathrm{~b}$ & $2 \mathrm{~b}$ \\
T6 & $3 \mathrm{~b}$ & $1 \mathrm{~b}$ \\
\hline CV $(\%)$ & 67,07 & 87,17
\end{tabular}

Na coluna, médias seguidas de mesma letra, não diferem entre si pelo teste de Scott-Knott no nível de 5\% de probabilidade.
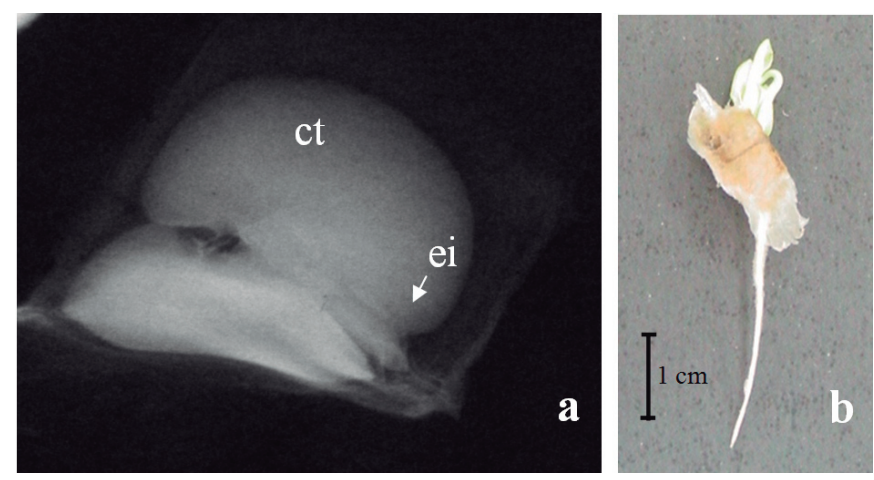

FIGURA 2. Sementes de ipê-roxo avaliada por meio do teste de raios $X$, com mais que $50 \%$ da cavidade embrionária preenchida e com comprometimento de um dos cotilédones (a) originando uma plântula anormal (b). ct - cotilédone; ei - eixo embrionário.

TABELA 3. Germinação (sementes mortas e notas 5 e 6 atribuídas às imagens das sementes no teste de raios $X$ ) de sementes de ipê-roxo separadas por coloração e tamanho (T1testemunha, T2 - sementes amarelo-claro maiores, T3 - sementes amarelo-claro menores, T4 - sementes amarelo-escuro maiores, T5- sementes amarelo-escuro menores e T6 - mistura dos tratamentos T2, T3 e T4).

\begin{tabular}{ccc}
\hline & \multicolumn{2}{c}{ Germinação (\%) } \\
\hline Tratamentos & Sementes mortas & Notas (5 e 6) \\
\hline T1 & $36 \mathrm{a}$ & $28 \mathrm{~b}$ \\
T2 & $25 \mathrm{a}$ & $14 \mathrm{~b}$ \\
T3 & $48 \mathrm{a}$ & $45 \mathrm{a}$ \\
T4 & $38 \mathrm{a}$ & $26 \mathrm{~b}$ \\
T5 & $35 \mathrm{a}$ & $27 \mathrm{~b}$ \\
T6 & $22 \mathrm{a}$ & $17 \mathrm{~b}$ \\
\hline CV $(\%)$ & 33,90 & 43,87 \\
\hline
\end{tabular}

Na coluna, médias seguidas de mesma letra, não diferem entre si pelo teste de Scott-Knott no nível de 5\% de probabilidade. 


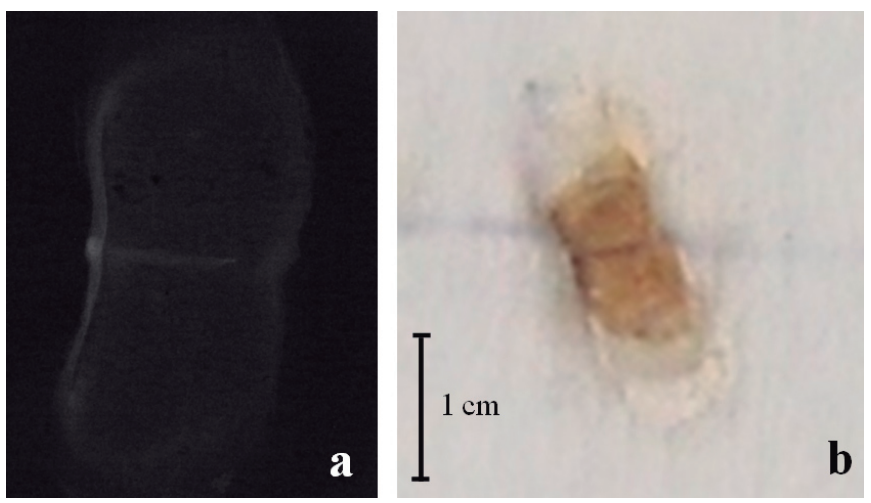

FIGURA 3. Semente de ipê-roxo avaliada por meio do teste de raios $X$, com a cavidade embrionária totalmente vazia (a) e semente morta ao final do teste de germinação (b).

Lopes et al. (2005) em seus estudos com sementes de Tibouchina granulosa observaram que o tamanho dos frutos e a coloração das sementes são indicadores do ponto de maturidade fisiológica. Adicionalmente, Martins e Silva (1997) relataram que o grau de umidade e a massa da matéria seca foram os parâmetros que melhor caracterizaram a maturidade fisiológica em sementes de Dalbergia nigra (Vell.) Fr. All.ex Benth.

Assim como Socolowski et al. (2008) observaram em sementes de Tecoma stans, as imagens de raios X em sementes de Tabebuia heptaphylla permitiram visualizar o grau de desenvolvimento dos embriões, possibilitando observar anomalias embrionárias, que provavelmente tiveram origem durante a maturação dos frutos.

\section{CONCLUSÕES}

- O teste de raios $\mathrm{X}$ é eficiente para avaliar a morfologia interna de sementes de ipê-roxo e sua relação com o potencial fisiológico.

- A coloração e o tamanho das sementes de ipê-roxo influenciam o potecial fisiológico das mesmas.

\section{REFERÊNCIAS}

BRASIL. Ministério da Agricultura, Pecuária e Abastecimento. Regras para análise de sementes. Ministério da Agricultura, Pecuária e Abastecimento. Secretaria de Defesa Agropecuária. Brasília, DF: MAPA/ ACS, 2009. 395p.
BURG, W.J. van der; AARTSE, J.W.; ZWOL, R.A. van; JALINK, H.; BINO, R.J. Predicting tomato seedling morphology by X-ray analysis of seeds. Journal American Society for Horticultural Science, v.119, n.2, p.258-263, 1994.

CARVALHO, N.M.; NAKAGAWA, J. Sementes: ciência, tecnologia e produção. 4.ed. Jaboticabal: FUNEP, 2000. 588 p.

CARVALHO, M.L.M.; VAN AELST, A. C.; VAN ECK, J. W.; HOEKSTRA, F. A. Pre harvest stress cracks in maize (Zea mays L.) kels as characterized by visual, $\mathrm{X}$-ray and low temperature scanning electron microscopical analysis: effect on kernel quality. Seed Science Research, v.9, n.3, p. 227-236, 1999.

CICERO, S. M.; VAN DER HEIJDEN, G. W. A. M. ; VAN DER BURG, W. J.; BINO. R.J. Evaluation of mechanical damages in seeds of maize (Zea mays L.) by X-ray and digital imaging. Seed Science and Technology, v.26, n.3, p.603-612, 1998.

COPELAND, L.D. Principles of seed science and technology. Minneapolis: Burges Publishing Company, 1976. 369p.

GEMARQUE, R.C.R.; DAVIDE, A.C.; FARIA, J.M.R. Indicadores de maturidade fisiológica de sementes de Ipêroxo (Tabebuia impetiginosa (Mart.) Standl.). Cerne, v.8, n.2, p.32-40, 2002. Disponível em $<$ http://redalyc.uaemex. mx/pdf/744/74480207.pdf>. Acesso em: 12 fev. 2011.

ISTA - INTERNATIONAL RULES FOR SEED TESTING. Seed Science and Technology. Zurichstr.50, edition 2009.

LOPES, J.C.; DIAS, P.C.; PEREIRA, M.D. Maturação fisiológica de sementes de quaresmeira. Pesquisa Agropecuária Brasileira, v.40, n.8, p.811-816, 2005. Disponível em <http://www.scielo.br/pdf/pab/v40n8/ a12v40n8.pdf>. Acesso em: 13 fev. 2011.

LORENZI, H. Árvores Brasileiras: manual de identificação e cultivo de plantas arbóreas do Brasil. 2. ed. São Paulo: Nova Odessa, 2002. v.2. 384p.

MACHADO, C.F.; CÍCERO, S.M. Aroeira-branca (Lithraea molleoides (Vell.) Engl. - Anacardiaceae) seed quality evaluation by the X-ray test. Scientia Agricola, v.60, n.2, p.393-397, 2003. Disponível em <http://www. scielo.br/pdf/sa/v60n2/15344.pdf $>$.

MARTINS, S.V.; SILVA, D.D. Maturação e época de colheita de sementes de Dalbergia nigra (Vell.) Fr.All.ex Benth. Revista Brasileira de Sementes, v.19, n.1, p.96-99, 1997. Disponível em: <http://www.abrates.org.br/revista/ 
artigos/1997/v19n1/artigo18.pdf> .

MASETTO, T.E.; FARIA, J.M.R.; QUEIROZ, S.E. Avaliação da qualidade de sementes de cedro (Cedrella fissilis - Meliaceae) pelo teste de raios X. Ciência e Agrotecnologia, v.32, n.6, p.1-7, 2008. Disponível em $\quad<$ http://www.scielo.br/scielo.php?script=sci arttext\&pid=S1413-70542008000600004>.

MASETTO, T.E.; DAVIDE, A.C.; SILVA, E.A.A.; FARIA, J.M.R. Avaliação da qualidade de sementes de Eugenia pleurantha (Myrtaceae) pelo teste de raios X. Revista Brasileira de Sementes, v.29, n.3, p.170-174, 2007. Disponível em <http://www. scielo.br/scielo.php?script $=$ sci_arttext\&pid $=$ S010131222007000300020>.

MUNSELL COLOR COMPANY. Macbeth, Division of Kolmorgen Instruments Corporation. Munsel. Soil Color Charts, New Windsor, 1994. 1v.

OBANDO FLOR, E.P. Danos internos de secagem avaliados pelo teste de raios $X$ e seus efeitos na qualidade de sementes de milho armazenadas. 2000. 62f. Dissertação (Mestrado) - Universidade Federal de Lavras, Lavras, 2000.

OLIVEIRA, L.M.; CARVALHO, M.L.M.; DAVIDE, A. A utilização do teste de raios-X na avaliação da qualidade de sementes de canafístula (Peltophorum dubium (Sprengel) Taubert). Revista Brasileira de Sementes, v.25, n.1, p.116-120, 2003. Disponível em <http://www.scielo.br/ pdf/rbs/v25n1/19639.pdf>.

OLIVEIRA, L.M.; CARVALHO, M.L.M.; GUIMARÃES, R.M.; MASETTO, T.E. Avaliação da qualidade de sementes de Tabebuia serratifolia Vahl Nich. e T. impetiginosa (Martius ex A. P. de Candolle) Standley - (Bignoniaceae) pelo teste de raios X. Revista Brasileira de Sementes, v.26, n.2, p.138-143, 2004. Disponível em: $<$ http://www. scielo.br/scielo.php?script $=$ sci_arttext\&pid $=\mathrm{S} 0101-31222$ 004000200019\&lng=en\&nrm $=\bar{i}$ so\&tlng $=$ ptpt $>$.

SIMAK, M.; BERGSTEN, U.; HENRIKSSON, G. Evaluation of ungerminated seeds at the end of germination test by radiography. Seed Science and Technology, v.17, p.361-369, 1989.

SOCOLOWSKI, F.; CÍCERO, S.M. Caracterização morfológica de embriões por imagens de raios $\mathrm{X}$ e relação com a massa e a qualidade fisiológica de sementes de Tecoma stans L. Juss ex Kunth (Bignoniaceae). Revista Brasileira de Sementes, v.30, n.2, p.200-208, 2008. Disponível em $<$ http://www.scielo.br/pdf/rbs/v30n2/a25v30n2.pdf $>$.

VAUGHAN, C.E.; GREGG，B.R.; DELOUCHE，J. Beneficiamento e manuseio de sementes. Brasília: AGIPLAN, 1976. 195p. 